\title{
The Chagga people and environmental changes on Mount Kilimanjaro: Lessons to learn
}

\author{
LEA SEBASTIEN, PhD
}

Associate professor, University of Toulouse 2, GEODE Research Center (Environmental Geography), 5 Antonio Machado Street, 31058 Toulouse, Cedex 09, France

lea.sebastien@univ-tlse2.fr

Mount Kilimanjaro, the highest mountain in Africa, is a site of exceptional diversity. However, its fragile balance is presently under threat, mainly from hydrological issues. Scientists and politicians have different hypotheses concerning the condition and availability of water on the mountain, thus far without consensus. Some of these hypotheses infer that the local Chagga communities living on Kilimanjaro's slopes are implicated in the overall degradation of natural resources. A major part of the research presented in this paper focuses on the Chagga people's view of their environment. The research uses the Actor in 4 Dimensions (A4D) methodology. This multidisciplinary conceptual model helps one to understand a territory by analysing the relations between individuals (social link) and the relations between humans and no humans (natural link). This paper aims to (1) present the A4D model and its innovative methodology, (2) analyse the stakeholders' dynamics around environmental issues on the mountain and (3) focus on the Chagga's perception of natural resource evolution and management. The A4D results show that the Chagga display a profound attachment to their territory, the forest is the element creating social relations, technical progress can mean social regression, conflicts over natural resources are increasing and hydrological risks on Mount Kilimanjaro are primarily of a social nature.

Keywords: agroforestry; Chagga; environmental governance; hydrosystem; Kilimanjaro; social relations; sustainable development; territory

\section{Introduction}

With changes in global climate, the snowcap on Mount Kilimanjaro has dramatically decreased in size and Mount Kilimanjaro is today a focus of world attention. Not since Hemingway has the biggest isolated mountain in Africa been so talked about. At 5,895 m, located in northeastern Tanzania, Mount Kilimanjaro is Africa's highest peak. The diversity of its nature is exceptional: from lowland savannah to upper icecap, a huge range of ecosystems is represented in its slopes. But today, this treasure is threatened. Since it was first measured in 1912 (Klute, 1920), the snowcap had lost 82 per cent of its volume by 2000 (Thompson et al., 2002), and the impact of this on the hydrosystem and the overall environment is still unknown. Meanwhile, the town of Moshi, located at the base of the mountain, has experienced water shortages. Integrated into the Pangani water basin, Mount Kilimanjaro is the major water supply for Tanzania and East Africa. A decrease in this resource could produce devastating impacts and serious hydrological risks. The mountain provides shelter to the Chagga, a people who have been cultivating parcels of land on its slopes for centuries. Until now, access to water in villages has traditionally been managed by canal committees, a type of social platform aiming at organizing irrigation among users. As human activity intensifies and the high altitude forest is nibbled away, as snow disappears and as new stakeholders appropriate resources, the situation is not as serene as before and water is becoming scarce. At the local level, how do actors perceive the problem? How do local populations react on a day-to-day basis? Do these environmental preoccupations provoke conflicts? Are these hydrological risks aggravated by social aspects? Overall, what links can be established between the sociosphere and the biosphere on Mount Kilimanjaro?

This article aims to evaluate how relevant actors perceive environmental and social issues on Mount Kilimanjaro. To do so, Section 2 outlines the challenges that face Mount Kilimanjaro as well as the methodology used in the research - a model named Actor in 4 Dimensions (A4D). Section 3 presents the use of the A4D model to study the environmental governance of a given territory. Section 4 provides an 
analysis of stakeholder dynamics around natural resource management on the mountain. Section 5 focuses on local communities' perceptions of their environment in order to help understand the causes of ecological degradation, and to propose recommendations for better environmental governance of Kilimanjaro's slopes. Section 6 offers some conclusions.

\section{The challenges faced by Mount Kilimanjaro}

Mount Kilimanjaro represents the main source of water for the Pangani river basin, which has a total area of 42,200 km2 (including 2,320 km2 in Kenya). Tanzania depends mainly on that basin for hydropower generation (Maganga et al., 2004). It is also within the northern tourist area, one of the most visited areas in Tanzania, and contains the Arusha and Moshi industrial municipalities.

A sizable area is also used for traditional livestock rearing, an important component in overall basin water management. In addition to its important cultural and spiritual significance, Mount Kilimanjaro is the primary source not only of water but also of food, fuel and building material for the people of northcentral Tanzania. However, the capacity of the mountain to continue to provide these vital products and services is threatened by inappropriate use and over exploitation of many of its natural resources (Newmark and Leonard, 1991). Several studies conducted by both hydrologists and environmentalists (e.g. Mkhandi and Ngana, 2001) show that there is water stress in the Pangani basin because all major sources of water supply are endangered by environmental degradation.

As a result, water management in the basin has to balance between demands for (i) coffee and banana cultivation on the slopes of Mount Kilimanjaro, (ii) paddy farms in the lowlands, (iii) flower cultivation around Arusha and (iv) hydropower plants at Nyumba ya Mungu, Hale and Pangani Falls (Mbonile, 2005). As a consequence of these competing needs, sectoral water demands are not being met and water levels in storage reservoirs are low (Madulu, 2003). To better manage water, the Tanzanian government launched the National Water Policy in 1991, which put an end to the era of free water (begun in 1967) and introduced the principle of cost sharing in the operations and maintenance of water schemes. The revised 2002 Water Policy puts emphasis on a demand-responsive approach and community participation in the management of water schemes (URT, 2002). However, the impacts of this policy do not appear to have had a positive effect, as conflicts are increasing and resources are dwindling.

The causes for environmental degradation are numerous and hardly settled: massive deforestation, conifer plantations, a growing human population, changes in land use, evolution of agricultural systems and rivers being diverted. On Kilimanjaro's slopes live the Chagga people. Their population increases at an estimated rate of 3 per cent each year (Price and Butt, 2000) and the population density for the upper belt was around 650 people per $\mathrm{km} 2$ in the year 2000, according to the Moshi Rural District Council. Consequently, the land devoted to agriculture, which the Chagga call shamba, is shrinking. Yet, the old Chagga agroforestry system has been one of the most productive areas of agriculture in Tanzania. Its multiculture combination of trees, rice, vegetables, beans and groundnuts combines well with naturally good soil to achieve sustainable resource management (Hemp, 2006).

In parallel, the Kilimanjaro region has a long tradition of gravity-fed irrigation canals (mifongo), with some schemes dating back to the $17^{\text {th }}$ century. These canals are important elements in the cultural and technological heritage of the Chagga, who for centuries have utilized a network of these canals for irrigation and other purposes (Tagseth, 2002). The allocation of water between the furrows is based on customary laws and behavioural norms of the community. However, with the added issues of low coffee prices and lack of water, both the agroforestry and irrigation systems are disappearing gradually.

The overall environmental degradation is striking, despite the fact that Mount Kilimanjaro was classified as a natural reserve in 1921, a National Park in 1973 and a World Heritage Site by UNESCO in 1989. Chagga communities are tolerated on a 'half-mile strip' of the forest reserve, where they are allowed to collect fallen branches for firewood (Figure 1). The above classifications implied modifications of stakeholder dynamics in the area and shifts in responsibilities. What are the local populations living on the highest mountain in Africa willing to accept with respect to environmental risk? What kind of environmental governance can be implemented on the Kilimanjaro slopes? Our methodology aims at 
understanding the overall stakeholder dynamics on the slopes of the mountain, and particularly the position of the Chagga people in these dynamics.

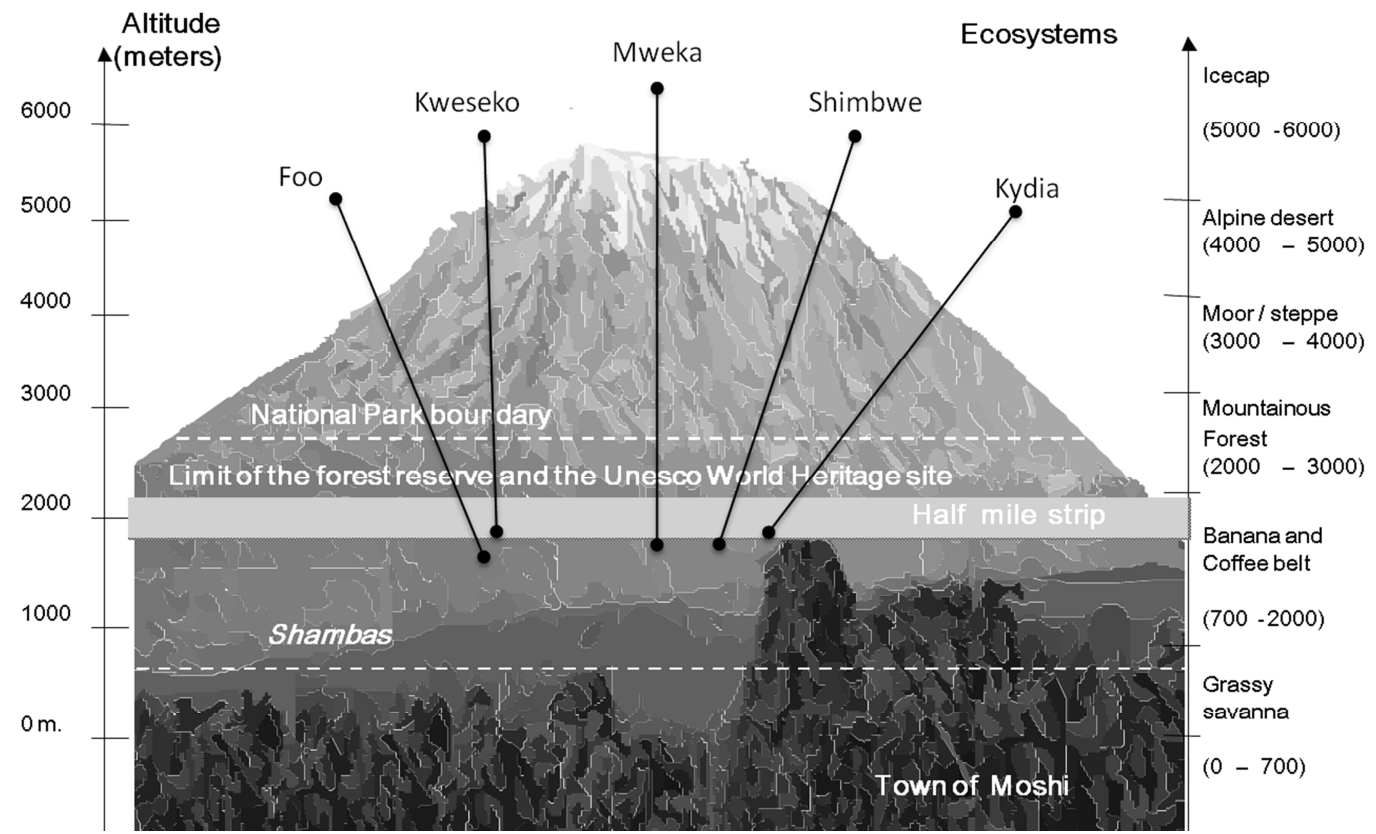

FIGURE 1 Schematization of the field of study

Source: Léa Sébastien.

\section{A special methodology for a special field of study}

The research presented in this article aims to study the relationships that exist between actors on the mountain and between people and nature. In order to reach this objective, we have designed a theoretical and methodological model called A4D (Sébastien, 2007a). This multidisciplinary conceptual model has the aim of comprehending a territory through analysis of relations between individuals (social links) and relations between humans and non-humans (natural links) (see Figure 2). In this case, it focuses on water problems, analyses interactions between stakeholders within the hydrosystem and provides tools to facilitate an environmental negotiation.

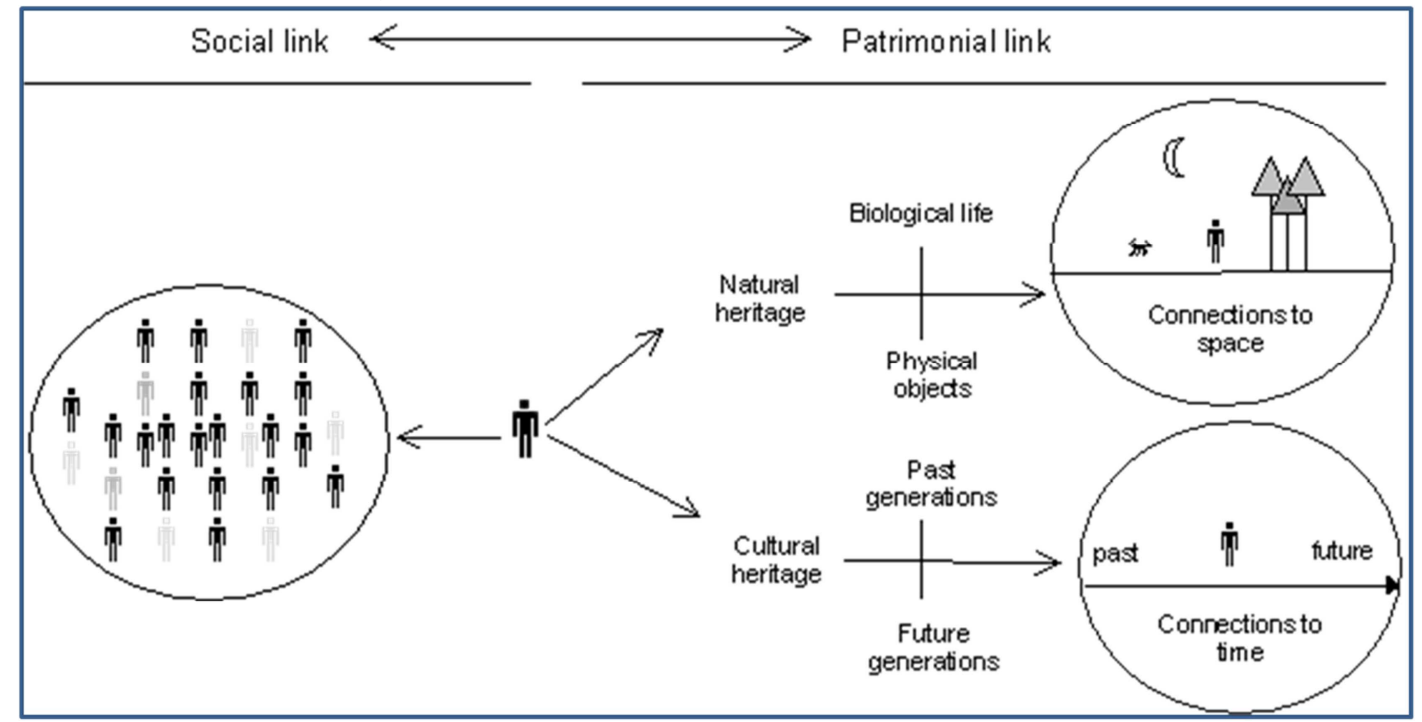

FIGURE 2 Explanations of social and natural links

The A4D results can be visualized by the 'territorial footprint', a graphical representation illustrating social and natural links in a territory. Each actor has its own territorial footprint, obtained through the 
compilation of 111 indicators, 32 variables and eight sub-dimensions to make the model reflexive and dynamic (see Figure 3). All these descriptors provide information on the overall tendencies of actors in the four dimensions of the model: cooperation and conflict (social link), and cohabitation and domination (natural link). The territorial footprint can be described as an x-ray photograph, because it positions an actor at a specific moment in time, a synchronic vision of the tendencies of one actor towards others and towards the territorial environment, specifically the water resource in this case.

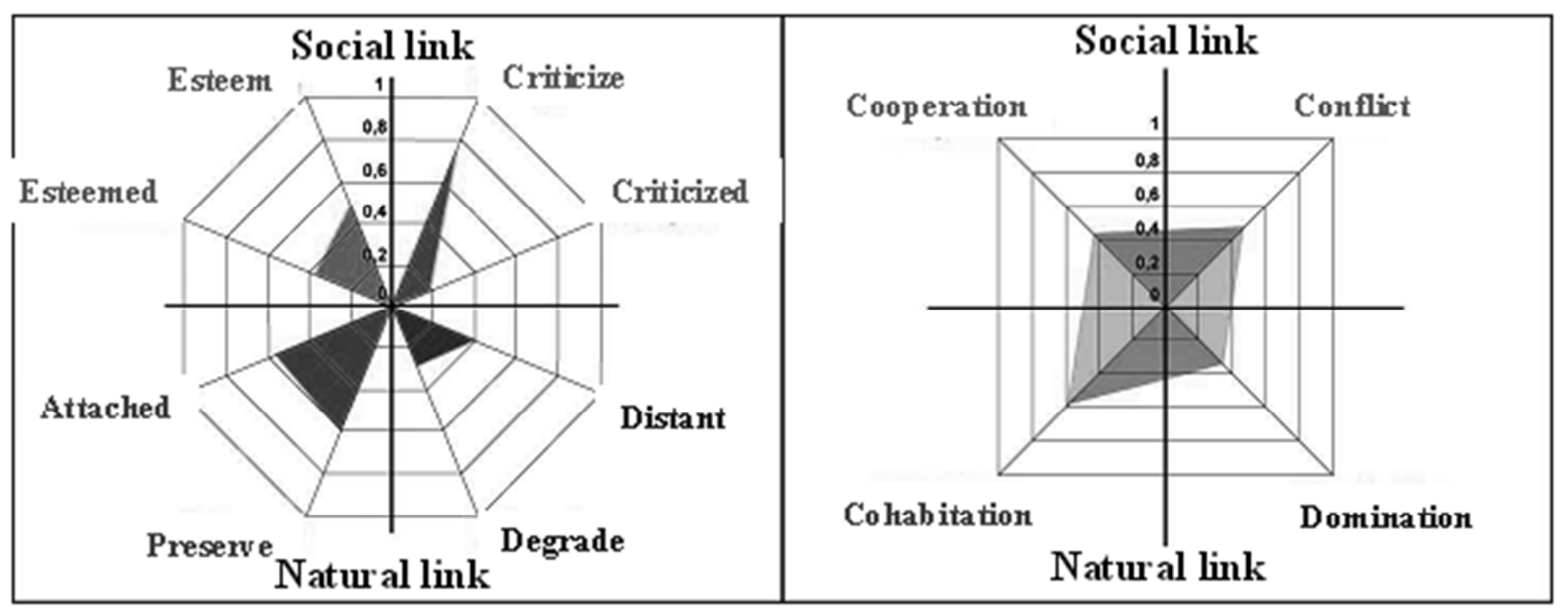

FIGURE 3 The territorial footprint of Chagga people (right: 4 dimensions/left: 8 dimensions)

This model could be of potential interest for a project organizer, a negotiator or a mediator as well as for actors themselves. Among its operational benefits, the A4Dmodel can reveal important information about the actors' interactions and enhances dialogue between stakeholders on a given environmental issue. To implement the A4D model on Mount Kilimanjaro, key actors were identified and meetings were organized between them. Interviews were conducted using a complex but focused interview guide, inspired by the patrimonial strategy1 (Ollagnon, 1989). The final task was to transform speech into data using an adapted database in order to classify oral information. The discursive information was filtered into the actors' practices (actions, projects of actors concerning natural resources and the social complex), preferences (perceptions, representations of actors concerning natural resources and the social complex) and knowledge (types of knowledge actors use concerning natural resources and the social complex: institutional, traditional and scientific) (Donnadieu, 2002). Three types of results were expected: (1) an analysis of stakeholder dynamics (i.e. influences and dependencies among strong, weak and absent actors); (2) differences in knowledge, practices and preferences among actors; and (3) analysis of territorial footprints for each actor according to the A4D model. The objective was to analyse the social and natural links on the territory in order to evaluate the environmental governance potentialities.

Themethods were tested on the southern slopes of Mount Kilimanjaro in 2005, with the support of an English-Swahili translator. Personalized interviews were conducted among representatives of the associative, industrial, agricultural and institutional fields. Seven groups of actors engaged in the administration of the Kilimanjaro region were involved: the TanzanianAssociation of Foresters (TAF), the Kilimanjaro National Park (KINAPA), the Tanzanian Coffee Board (TCB), Bonite Bottlers Inc., the Pangani Basin Water Office, the hydrology service (PBWO), scientists from Dar Es Salaam University and the village officers.

After these interviews, and using the same methodology, analysis of the Chagga's views on their environment was carried out. Since the Chagga people are not organized as associations or pressure groups, interviews were conducted in 50 households in order to be able to understand the various relationships between individuals and their territory. We met 50 Chagga families in five different villages (Shimbwe, Kidia, Mweka, Foo and Kweseko, see Figure 4), all located at the limit of the 'forbidden' zone at around 2,000 $\mathrm{m}$ in altitude. Interviewees were (1) people of the highlands, because they are the first witnesses of environmental changes on the mountain, and (2) people over 50 years old, in order to analyse the evolution of the environment through time. 
Interviews were not recorded but transcribed, an efficient method where translation is necessary. The focal point of this survey was the essence of the relations that actors have developed with others and with the natural assets of their locality. From this, the evolution of water and wood uses over time, management strategies, perceptions of hydrological risks and the challenges facing Mount Kilimanjaro could be identified. The database was essentially qualitative and provided data on the role of each interviewed actor about (1) the territory (perceived problems locally and globally, actors' goals and propositions, values and connections to time), (2) the social stage (actors criticized and complimented, perceived image of others and of themselves, conflicts engaged, and (3) the hydrosystem (issues pointed out spontaneously, points emphasized after questions). It took five months to carry out the surveys and classify the data.

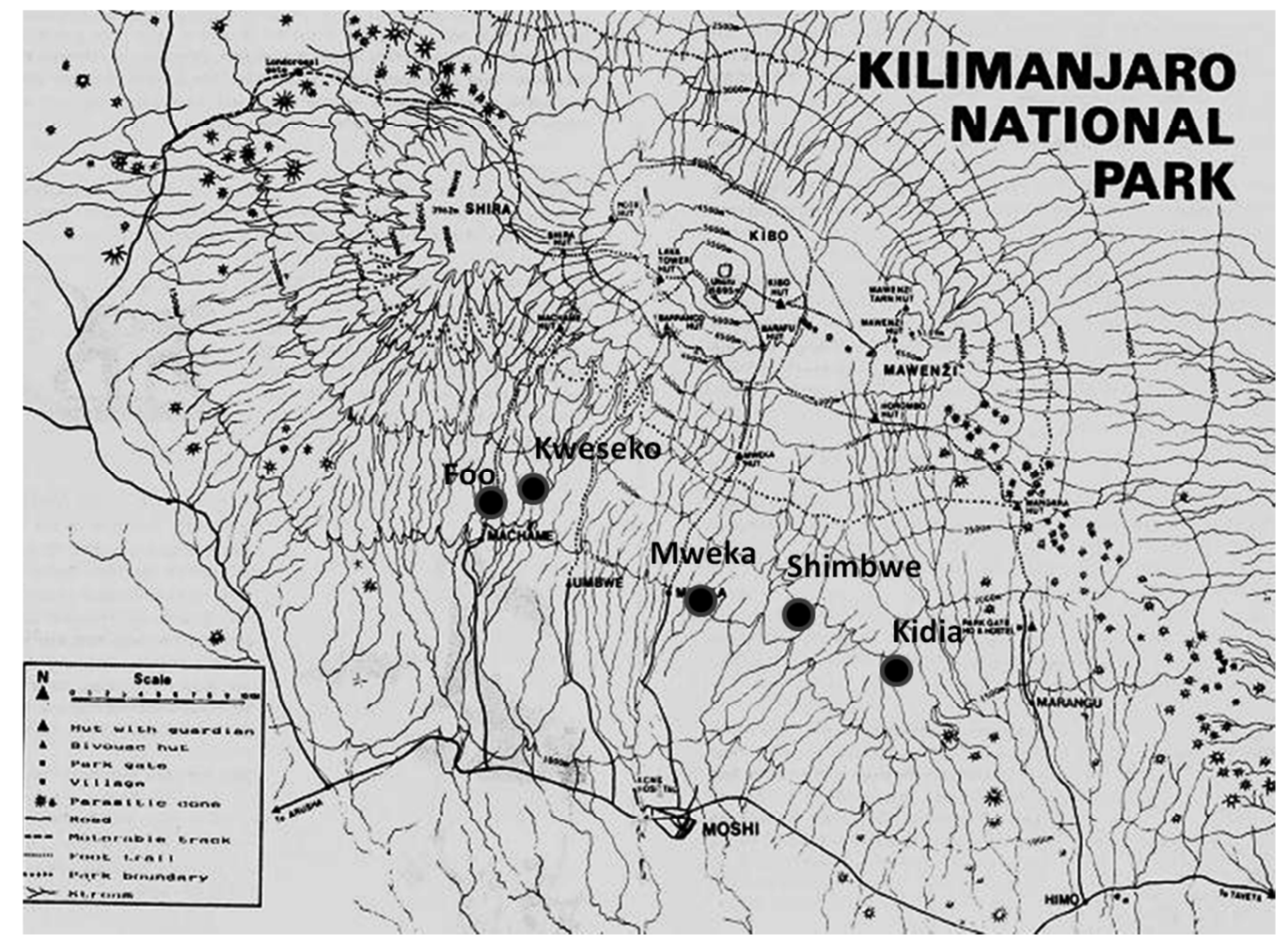

FIGURE 4 Location of the five villages on the south slopes of Mount Kilimanjaro Source: Kinapa.

\section{Results: what the discourses reveal \\ 4.1. Talking about hydrological risks}

When asked about problems on the mountain, all categories of actor (Chagga, authorities, associations, industries) spoke spontaneously and systematically about hydrological risks: that it is a novel phenomenon. Even if researchers have not reached definite conclusions about the evolution of the hydrosystem, it is the first time that authorities admit it: there is a major problem of degradation of the water resource on Mount Kilimanjaro. In terms of hydrological risks, the actors' answers can be categorized into four areas. All actors stated concern about the overall diminution of water, which can be observed directly through the decrease in river flow and disappearing sources and canals. As for the main Pangani river, it is reported that the flow has decreased over the last four decades from several hundred to less than $37 \mathrm{~m} 3 / \mathrm{s}$ (UNEP, 2009). Such a situation is of concern for users and for both the scientific community and the Tanzanian government. Researchers from Dar es Salaam University suspect that the general hydrosystem has been transformed mostly because of a change in the reservoir system of the mountain. In 2001, the PBWO reported for the first time a general degradation of natural resources, especially in regard to the amount and quality of water. 
The second type of problem that concerned actors relates to climate: climate change and melting icecaps. Stakeholders point to global issues to explain the lack of water, even if the exact causes and consequences of the melting of the snow cap and of the changes in the microclimate are still controversial among scientists. Nevertheless, studies predict that the Kilimanjaro icecap will have disappeared before 2040 (Thompson et al., 2002). Linked or not with that issue, the climate is said by actors to have become dryer, and hotter in summer and colder in winter. The temperature maps of Hay et al. (2002) in the Kilimanjaro area for the period 1941-1995 indicate an increase mean daily maximum temperature at a rate of 2.758C per decade. In addition, rainfall data located on Mount Kilimanjaro reveal declining trends of between 2.5 and $12 \mathrm{~mm}$ per year at least during the last 60-100 years (Shaghude, 2006).

The third type of problem the actors referred to is the impact of human activity on the environment, such as deforestation, land repartition and agricultural pollution. Even if the interrelations between highaltitude forest and water availability are still unclear, all the actors in the study suggest a clear and direct link between deforestation and lack of water. In fact, Kilimanjaro presents a high level of endemism for bryophytes, and both mosses and lichen play a critical role in intercepting rain (Pocs, 1998).

However, industry logging has transformed significantly the altitude ecosystem on the mountain slopes (Mwasaga, 1991). Furthermore, since the 1960s, there has been a steep increase in the clearing of forested land adjacent to rivers and streams for cultivation and collection of fodder (Zolongo et al., 2000). Finally, there is a significant increase in the number and intensity of wild fires on Mount Kilimanjaro. Although most of these fires are lit accidentally during human activities such as honey collection, poaching and grass burning during forest clearing for agricultural expansion (Hemp, 2005), their devastating effects are amplified by the dry weather conditions. As a result, degraded forest cover increased from 1,606 ha in 1973 to 5,170 ha in 2000 (Mbonile, 2005), while at least $41 \mathrm{~km} 2$ of natural forest having disappeared between 1952 and 1982 (Yanda and Shishira, 2001). Other significant changes are also evident in woodlands, bushlands and grasslands.

In the matter of land repartition, during the post-independence period large tracts of land were taken for the airport, for the country's vast wheat farms and for the national park and forest reserves. Land alienation has squeezed the local population into marginal lands, leading to further land degradation and water scarcity (Mbonile, 2005). Regarding agricultural pollution, farming systems are evolving rapidly on the south slopes of the mountain. Due to the high increase in population, the shambas are today on average less than 1 ha in size (IUCN, 2003), people cultivate more and more intensively in the lowlands, and coffee is being replaced by corn, except on coffee estates (vast and intensive government-run coffee plantations) (Soini, 2005).

Finally, actors point to social factors as aggravating hydrological risk. First of all, increasing conflicts over natural resources were emphasized and said to worsen environmental degradation on the south slopes of the mountain. Water-use conflicts erupt between upstream and downstream users about quantity and quality of water; between the rich and the poor in villages about inequalities of water access; between users and enterprises such as Kiliwater, which installed costly tapwater systems in villages; between users and water authorities about bad management; and between users and village officers about corruption. Many conditions may trigger water disputes, such as competition for scarce resources, differences in organizational status, unmet expectations, unequal power and authority, jurisdictional ambiguities, distortion in communication, misconceptions, and interdependence of people and tasks (Huggins, 2000). These factors rapidly overtake the social sphere and lead to practices that deteriorate the resource. Secondly, actors criticize the perceived bad management of natural resources on the Kilimanjaro slopes. KINAPA is accused of practising an economic sanctuarization: a false protected area only designed to be profitable. According to the KINAPA representative we met, among the 350 employees only one is a biologist and 300 are armed guards patrolling the area day and night to stop every trespasser except for tourists $(20,000$ trekkers climb the mountain each year). Villagers are allowed to gather deadwood only in the half-mile strip of the ancient communal forest, today managed by district councils. These local politicians are criticized for being corrupt, for not supporting the villagers and for transforming the social forest into a commercial forest.

Globally, hydrological risks are of concern for all actors interviewed on the south slopes of Mount Kilimanjaro, and they are explained by diverse environmental and social factors. All actors agree that 
there are real problems with the hydrosystem, even if the issues pointed out by stakeholders vary: for example, water quality, climate change, melting of the icecap, hydrological stress and conflicts. Research on these themes has not reached a consensus, but all actors in the locality (Chagga, authorities, associations and industries) unanimously agree that water resources are decreasing on the slopes and that high-altitude forest must be preserved.

\subsection{Overall actors' dynamics: Economics against traditional values}

On the mountain, the forest is a vital part of any discussion about water. Even if hydrological risks are systematically underlined by all types of actors who are concerned by water problems, the forest is key to an understanding of all social interactions, whether conflictual or cooperative. The interviews showed that it is neither the icecap nor the rivers that provoke the most heated discussions, but the forest: it integrates sacred values and is the entity that creates social links. On a substantive level, everyone wants to preserve high-altitude forests. On a procedural level, people fight over the methods to achieve this goal. This turmoil around forest preservation hides a profound opposition between tradition and modernity. Actors are divided into two groups: on the one hand, actors in favour of a modern society, encouraging intensive agriculture, industrial logging, conifer plantations, tourism development and installing water taps; in the other actors in favour of traditional activities attached to the ancestral type of canal management, transmission of oral knowledge, small agricultural land-parcels, agroforestry, village committees and indigenous trees.

These notions of conservation can be considered opposites. The worlds of industry, agriculture and tourism, which are strong actors in this field of study, can be described as unrooted: they do not consider territory on a global level, they are centred on their activity and they view their environment as a source of income. On the contrary, the world of users is rooted: these weak actors are attached to their territory and they associate existential values to their environment. Finally, there are relay actors, 'floaters' represented by associations and institutions: actors who display theoretical knowledge about the territory without any hands-on knowledge. According to the A4D model, the dynamics of stakeholders are mainly structured by the dimension of conflict, all actors being both criticized by others and critical towards them. The principle of negotiation seems compromised on the subject of environmental degradation, especially when it comes to the water resource. According to many stakeholders, the culprit for environmental problems is the Chagga peasant. 'Rural communities do not see the point of preserving Mount Kilimanjaro; they prefer using all National Park resources for their day-to-day needs. Therefore we must absolutely change their perceptions' (TANAPA, 1992). To slow down the degradation process, associations and local authorities started to implement environmental awareness programs targeting local populations. The Chagga peasant seems to be on trial, feeling almost undesirable on the slopes of the mountain. Are the inhabitants the right target?

It is generally assumed that local populations in developing countries are responsible for environmental degradation. Agricultural changes in areas with poor farmers are often associated with land degradation (Cleaver and Schreiber, 1994) and landscape fragmentation (Nagendra et al., 2004). According to all the models, a demographic increase implies a deterioration of natural resources through deforestation, overgrazing, etc. 'On a short term basis, peasants are forced to cultivate parcels in forest or on steep slopes. This ecological decline enhances poverty because degraded ecosystems provide only low harvest' (Brown, 1990). This vicious circle of 'demographic increase - poverty - environmental degradation' is commonly underlined to justify national regulation programs, but it may be an easy cliche' (Mathieu, 1998). Some studies try to demonstrate the contrary (e.g. Tiffen et al., 1994, in Kenya), which provides evidence over a long period of time that population, while imposing pressure on the land, neither degraded it nor precipitated precarious survival. Many complex quantitative and qualitative connections exist between local populations and their environment (Lee et al., 2001). The qualitative links, being harder to discern, are often forgotten. The final objective of the research was to analyse how the Chagga relate to their environment. The analysis goes beyond the familiar view of these issues in an attempt to understand the practices of the local population, but also the affective link that people display towards their environment. 


\section{Chagga: Small peasant, big culprit? 5.1. The Chagga territorial footprint}

The Chagga synthetic territorial footprint (Figure 3) is the result of the compilation of 50 interviews organized in five villages. It describes the tendencies of a Chagga peasant towards the other stakeholders (social link) and towards the environment (natural link). In the cooperation dimension, even if the actor appreciates few stakeholders on the territory, he wishes to join common projects and has a very good opinion of discussion and conciliation (subdimension empathic).'Kinapa guards are corrupted and violent towards us; they are nasty but protect the forest' (ind362). 'I would like to participate to collective projects' (ind12). In return, peasants are rarely appreciated by other stakeholders, who usually do not recognize any of their qualities such as local knowledge and understanding (sub-dimension esteemed). They are victims without access to water, forest or quality agriculture (TAF). In the conflict dimension, even if he does not know much about the social organization of his territory, a Chagga criticizes many actors and identifies his opponents with precision (subdimension critical). 'Water belongs to the mountain, but it has been stolen by Water Authority, which sells it' (ind2). 'Since government installed a water tank in the village, our irrigation canals have disappeared' (ind22). 'We only have access to dead branches on the ground, but we are stopped by KINAPA guards before entering the forest' (ind8). Chagga are also frequently criticized by others and therefore implicated in many major conflicts in the territory over deforestation, pollution or parcelling out of land or traditions (sub-dimension criticized). 'Villagers burn everything to cultivate everywhere' (TCB).

'Because of their traditions, they refuse to migrate elsewhere and they are going to kill agriculture on the mountain' (PWBO). Within the social dynamic, the Chagga feel isolated and dependent, and lack freedom. The natural links for this actor is characterized by the cohabitation dimension. The actor shows a profound and sometimes irrational attachment to many objects of the territory such as canals, forest, spring and atmosphere, and 'feels' the existing links between these objects (subdimension attached). 'I will die here, no matter what happens' (ind43). He precisely identifies all environmental threats and shows important traditional knowledge about the evolution of natural resources. High-altitude forests play an important role in the protection of mountains, micro-climate, fertile soil and springs. 'It is imperative that we protect it' (ind33). He tries to involve himself in environmental protection projects,

but his actions are not recognized by others (sub-dimension preserve).

On the domination side, he rejects new objects from modernity such as tourism, water tanks, 'modern trees, modern cows' (sub-dimension distant), and even though he tries to limit his impact on nature, he is seen by others as the one who he perceives to be causing degradation (sub-dimension degrade). 'I hate these modern trees; they dry out our springs' (ind7). For him, nature represents existential values, and he is willing to sacrifice a lot of his traditions for the sake of natural resources. 'If the snow cap melts, the Kilimanjaro will be a desert' (ind27).

It is interesting to note that the Chagga people situate themselves on vast scales in terms of space and time. First, they establish connections between local, national and global environmental issues. Even if the Chagga peasant spends his life on his shamba, he is aware not only of local problems but also of issues in the lowlands, in Tanzania as a whole, and even of global issues such as climate change or transboundary pollution. Second, the Chagga people are able to talk about past practices, as well asto project themselves into the future. In doing so, they manage to identifying connections between short-term and long-term stakes.

\subsection{Access to water, land and forest}

For the Chagga families interviewed at an altitude of 2,000 $\mathrm{m}$ and upwards, access to natural resources represents the basis of their existence, particularly water, land and wood. Their water concerns are about the number of springs decreasing, diminished rainfall and an overall weakness in river flow. Almost all families in our sample of villages are facing the disappearance of their irrigation canal. The first reason put forward is the installation of water taps by industries that directly transfer water from altitude sources to 
a reservoir. Consequently, water is no longer free, which modifies the link to this resource. Hence many shambas are not irrigated and canal committees, an ancestral communal system structured by a complex social hierarchy, disappear. Many studies on these canal committees show that the system was ensuring carefully managed water and social equity (Mbonile, 2005). The National Water Policy is facing major resistance from traditional irrigational water users, who are often reluctant to apply for water rights. They believe that water is a gift from God, it cannot be owned by an enterprise and it must be governed by the principles of common property management (Juma and Maganga, 2005). The installation of water taps simplifies the social structure of water management: those who can pay have water; others have to manage some other way. Therefore, technical progress leads to social regression on the slopes of Mount Kilimanjaro.

Concerning access to land, the family shamba presents a complex system of agroforestry (trees-bananacoffee-beans), a traditionally sustainable system that is being replaced by monoculture. Thirty years ago, the Tanzanian government encouraged coffee plantations, but does not want to support these small parcels any longer. Coffee production is decreasing rapidly and corn is its substitute, a new crop that grows poorly in the shade. This transition would destroy crop diversity on the slopes and hasten soil erosion. Furthermore, with the parceling out of land, the average size of the shambas in our sample is around 0.7 ha (0.6 ha according to data from international union for conservation of Nature-ILICN, 2003), which is not sufficient to feed a whole family. The Chagga traditionally remained living on their sacred mountain. Nevertheless, for the first time, now only a single child stays on the shamba and the new generations come down the mountain to live in town, a situation that modifies the local economy and social structures. Seasonal emigration becomes a common phenomenon on Kilimanjaro, where people seek supplementary livelihood options in other parts of Tanzania but still maintain close ties with the land they own in the village, regardless of its size (Shaghude, 2006). Finally, concerning forest access, people trying to pick up firewood face violence on a day-to-day basis from the guards of KINAPA. The forest represents vital goods for villagers. Any measure limiting access should trigger a strong reaction.

Surprisingly, even if 88 per cent of our sample consider access to the forest very dangerous and admit being either assaulted by KINAPA guards or having to bribe them, 71 per cent are still in favour of this National Park. According to Nash (1989), local populations are usually against the establishment of protected areas on their territory.

Our field research proves the contrary. 'Guards are violent towards us but if it's for the good of the forest, we can accept it' (ind13). The villagers remain in favour of a return to the traditional, communal management of the forest, but in theory only. Interviews revealed a fear of authority associated with mistrust in themselves: the Chagga peasant does not feel able to sustainably manage the forest any more and he does not believe in a truly social forest existing as it did in the 1940s. When the forest was managed by villagers themselves, people would respect the rules in order to conserve the forest, but also to keep their social standing. Today, cutting a tree would go against the government and not against the community.

\subsection{Towards protecting the human-nature relationship}

Connections to biological life are sometimes described as social interactions (Descola and Palsson, 1996). This seems to be the case with the Chagga people. This research underlines the fact that the Chagga are profoundly attached to their environment, an attachment based on cultural, social and symbolic values as well as on survival instinct. They know that their survival depends directly on the hydrosystem and on the high-altitude forests. Besides, they display a vast knowledge of their environment and their traditional practices try to respect natural resources.

We could qualify this situation as a cultural or survival sustainability (Sébastien, 2007b). On the southern slopes of the mountain, agroforestry techniques and social organization of irrigation canals demonstrated a sustainable system, but this situation is deteriorating. Since the creation of the National Park managed by KINAPA and the half-mile strip managed by district councils, the Chagga have been dispossessed of their responsibility for the area. Ever since the natural resources have been appropriated by the government, the Chagga feel that they have no more power on the slopes. Ever since local management 
committees disappeared, dialogue is dwindling in villages. Peasants have intensified their agricultural practices and try to get water and wood where they can, hoping not to be caught by guards. However, peasants are not the main culprits.

Obvious corruption among park guards, black market wood, illegal deforestation and vast coffee plantation estates are some of the issues fuelling conflicts among the stakeholders. Furthermore, National Park policies state clearly that local populations are excluded from the park zone, leaving nature untouched so as to attract more tourists. This kind of conservation project, which does not take into account local socio-economic dynamics, generates conflicts, modifies the human-nature relationship and leads to general environmental degradation (Gomez-Pompa, 1992). The same issues are revealed by current water management, where the Tanzanian government is attempting to establish formal legal systems, fix property regimes and formalize informal arrangements through institutions such as River Basin Boards (Juma and Maganga, 2005). Natural resource management in the Kilimanjaro region operated for centuries under a plural legal system, with interactions between state and customary and religious laws, and between formal and informal institutions (Boesen et al., 1999). The mainstream policies and laws continue to regard customary laws as a transient system expected to die out, despite the fact that these informal systems have proven to be successful in managing water in a sustainable way and with social equity (Van Koppen, 2004).

The 'tragedy of the commons' theory tries to demonstrate that a communal good can only deteriorate, each user wanting to use it more (Hardin, 1968), but we show here that privatization of land can lead to natural resource depletion and that communal system management can be sustainable. According to Ostrom et al. (1999), a community can reach sustainable management of common resources when based on agreed social rules. This was true for the forest half-mile strip when managed by villagers, for water when managed by local committees and for biodiversity through the agroforestry system of the Chagga people, which serves as refuge to grasshoppers and endemic species (Hemp, 2006). In this instance, natural resources were sustainably managed through the social link.

Scholars such as Heltberg (2001) have argued that 'common property systems deserve respect for their management, equity and insurance functions. Policymakers should refrain from undermining common property systems, and should consider providing them with legal recognition and other forms of support'. Conservation implies managing relations between mankind and nature, much more than managing nature itself, but the Tanzanian government has chosen a different model of conservation for Kilimanjaro. Many documented examples show that non-negotiation situations are costly in the long run, economically, ecologically and socially. In carrying out water, land and forest reforms, policy makers need to explore alternatives to formal property rights and in some cases protect common property systems (Maganga et al., 2004). If it is not already too late, it is the only way to implement sustainable resource management on Mount Kilimanjaro, based on a participatory approach.

\section{Conclusions}

This article had three main objectives: to present an original methodology studying environmental governance; to analyse the stakeholders' dynamics on the Kilimanjaro slopes; and to focus on local communities' perceptions regarding their environment. The A4D methodology is a social engineering model that aims to frame an environmental negotiation by studying the interactions between social links and natural links within hydrosystems. Being a vehicle of data and debate, our model is designed to be an operational tool for a mediator, transferable to other territories and other resources. The visual result, known as the territorial footprint, illustrates stakeholder involvement and interactions. The Kilimanjaro Mountain has a fragile but unique socio-ecological system, which is today threatened by hydrological risks. Even though some actors show strong attachment to the forbidden forest, conflicts arise over how to protect it. Hydrological risks are themost significant environmental issues on the mountain, directly linked with forest management. The forest is the emblem of the area, the object that creates social links on the Kilimanjaro slopes. Two main groups are in opposition regarding natural resource management: traditionalists and modernists. 
This article shows that the Chagga people have been wrongly accused by other stakeholders of being responsible for the overall degradation of the ecosystem. Beyond their strong attachment to nature local communities are willing to compromise in order to protect their resources. Mount Kilimanjaro, which has 'belonged' to theChagga for centuries, is slipping gradually out of their control. This has its roots in 1972 when the government created the National Park of Kilimanjaro, with unauthorized zones for the local populations but with opened roads for tourists. Since 1991, the National Water Policy seeks to institutionalize private property regimes for water users. Meanwhile, industrial deforestation goes on and intensive agriculture is subsidized. Preserving a common resource like water on Mount Kilimanjaro demands that all of the above factors are taken into account and that a new governance model is negotiated between all stakeholders.

This article argues that common resources managed by local users can be sustainable and that development projects should not focus exclusively on 'physical capital' but should integrate 'social and cultural capital' as well. It can be asserted that solutions to the water problems on Kilimanjaro are not mainly technological; they are also, indeed mostly, of a social nature. Nevertheless, the Chagga people have lost faith in the community for managing natural resources. Their traditional systems have proved to be sustainable and many authors argue that we should return to systems of common property and preserve customary laws. Local populations do not feel capable of leading natural resource management anymore. The Chagga people show tough resistance to the commercialization and privatization of water because they believe that the resource is sacred, but they do not oppose KINAPA, even though they are victims of guards' corruption and violence. They see it as a sacrifice for the sake of water and forest. Decision makers who imagine they can teach the Chagga how to manage their resources might be better served by listening to them instead.

\section{Acknowledgement}

Thanks to Hugues Sebastien who patiently reviewed language mistakes.

\section{Notes}

1. Translation of a French theory: 'la stratégie patrimoniale'.

2. 'ind 36' refers to the 36 th individual met among our 50 interviews within the Chagga community.

\section{References}

Boesen, J. F., Maganga, F. and Odgaard, R., 1999. Norms, organizations and actual practices in relation to land and water management in Ruaha river basin, Tanzania. Managing the Globalized Environment, T. Granfelt (ed.). Intermediate Technology Publications, London.

Brown, L., 1990. State of the World. World Watch Institute, Washington, DC.

Cleaver, K. M. and Schreiber, G. A., 1994. Reversing the Spiral: the Population, Agriculture and Environment Nexus in Sub-Saharian Africa. The World Bank, Washington, DC.

Descola, P. and Palsson, G., 1996. Nature and Society- Anthropological Perspectives. Routledge, London.

Donnadieu, G., 2002. La syste'mique: penser et agir dans la complexite'. Ed. Liaisons, Rueil Malmaison, France.

Gomez-Pompa, A., 1992. Taming the wilderness myth. Bioscience, 42(4). 271-279.

Hardin, G., 1968. The tragedy of the commons. Science, 162. 1243-1248.

Hay, S. I., Cox, D., Rogers, J., Randolf, S. E., Stern, D. I., Shanks, G. D., Myers, M. F. and Show, R. W., 2002. Climate change and the resurgence of malaria in the East African highlands. Nature, 415. 905-909.

Heltberg, R., 2001. Property rights and natural resource management in the developing countries. Journal of Economic Surveys, 16(2).189-214.

Hemp, A., 2005. Climate change-driven forest fires marginalize the impact of ice cap wasting on Kilimanjaro. Global Change Biology, 11. 1013-1023.

Hemp, A., 2006. The banana forests of Kilimanjaro: biodiversity and conservation of the Chagga homegardens. Biodiversity and Conservation, 15. 1193-1217. 
Huggins, C., 2000. Rural Water Tenure in East Africa: A Comparative Study of Legal Regimes and Community Responses to Changing Tenure Patterns in Tanzania and Kenya. Kenya African Centre for Technology Studies, Nairobi.

IUCN, 2003. Eastern African programme 2003. The Pangani River Basin: A Situation Analysis, ScanHouse Press Ltd. Nairobi

Juma, I. H. and Maganga, F. P., 2005. Current reforms and their implications for rural water management in Tanzania. Proceedings of the International Workshop African Water Laws: Plural Legislative Frameworks for Rural Water Management in Africa, 26-28 January, Johannesburg, South Africa.

Klute, F., 1920. Ergebnisse der Forschungen am Kilimandscharo 1912. Reimer, Berlin.

Lee, D. R., Ferraro, P. J. and Barrett, C. B., 2001. Introduction: changing perspectives on agricultural intensification, economic development and the environment. Tradeoffs or Synergies? Agricultural Intensification, Economic Development and the Environment, D. R. Lee and C. B. Barrett (eds). CABI publishing, Wallingford, Oxon. 1-16.

Madulu, N. D., 2003. Linking poverty levels to water resource use and conflicts in rural Tanzania. Physics and Chemistry of the Earth, 28. 911-917.

Maganga, F., Kiwasila, H. L., Juma, I. H. and Butterworth, J. A., 2004. Implications of customary norms and laws for implementing IWRM: findings from Pangani and Rufiji basins, Tanzania. Physics and Chemistry of the Earth, 29. 1335-1342.

Mathieu, P., 1998. Population, pauvreté et dégradation de l'environnement en Afrique: fatale attraction ou liaisons hasardeuses? Nature, Sciences, Sociétés, 6(3). 27-34.

Mbonile, M. J., 2005. Migration and intensification of water conflicts in the Pangani Basin, Tanzania. Habitat International, 29. 41-67.

Mkhandi, S. and Ngana, J., 2001. Trends analysis and spatial variability of annual rainfall. Water Resources Management in the Pangani River Basin: Challenges and Opportunities, J. Ngana (ed.). Dar es Salaam University Press, Dar es Salaam. 21-29.

Mwasaga, B. C., 1991. The natural forest of Mount Kilimanjaro. The Conservation of Mount Kilimanjaro, W. D. Newmark (ed.). IUCN Tropical Forest Programme, Gland.

Nagendra, H., Munroeb, D. K. and Southworth, J., 2004. Introduction to the special issue, from pattern to process: landscape fragmentation and the analysis of land use/land cover change. Agriculture, Ecosystems and Environment, 101. 111-115.

Nash, R., 1989. The Rights of Nature: A History of Environmental Ethics. University of Wisconsin Press, Wisconsin.

Newmark,W. D. and Leonard, N. L., 1991. Attitudes of local people toward Kilimanjaro National Park and Forest reserve. The Conservation of Mount Kilimanjaro, W. D. Newmark (ed.). IUCN Tropical Forest Programme, Gland.

Ollagnon, H. (ed.), 1989. Une approche patrimoniale de la qualite' des milieux naturels. Du Rural a` l'Environnement, la Question de la Nature Aujourd'hui, L. 'Harmattan,Paris. 258-268.

Ostrom, E., Burger, J., Field, C., Norgaard, R. and Policansky, D., 1999. Revisiting the commons: local lessons, global challenges. Science, 284. 278-282.

Pocs, T., 1998. Bryophyte diversity along the Eastern Arc. Journal of East African Natural History, 87(1). 75-84.

Price, M. F. and Butt, N., 2000. Forests in sustainable mountain development: a state of knowledge report for 2000. IUFRO 5, Research Series. CABI Publishing, Wallingford, Oxon.

Sébastien, L., 2007a. A qualitative methodology to facilitate environmental governance: the Actor in 4 dimensions model. Proceedings of the 8th Congress of the European Sociological Association (ESA), Glasgow.

Sébastien, L., 2007b. Relations homme-nature en milieux d'altitude: quand la durabilité est une question de survie. Cahiers de l'Afrique de l'Est 34, Gestion Des Ressources Naturelles. IFRA. 57-86.

Shaghude, Y. W., 2006b. Review of water resource exploitation and land use pressure in the Pangani river basin. Western Indian Ocean Journal, 5(2). 195-207.

Soini, E., 2005. Land use patterns and livelihood dynamics on the slopes of Mount Kilimanjaro, Tanzania. Agricultural Systems, 85. 306-323. 
Tagseth, M., 2002. Local practices and changes in farmer-managed irrigation in the Himo Catchment, Kilimanjaro. Water Resources Management - The Case of Pangani River Basin: Issues and Approaches. J. O. Ngana (ed.). Dar es Salaam University Press, Dar esSalaam. 48-63.

TANAPA, 1992. Kilimanjaro Draft General Management Plan. Tanzania National Parks, Planning Unit. Thompson, L. G., Mosley-Thompson, E., Davis, M. E.,

Henderson, K. A., Brecher, H. H., Zagorodnov, V. S., Mashiotta, T. A., Lin, P. N., Mikhalenko, V. N., Hardy, D. R. and Beer, J., 2002. Kilimanjaro ice core records: evidence of holocene climate change in tropical Africa. Science, 298(5593). 589-593.

Tiffen, M., Mortimore, M. and Gichuki, F., 1994. More People, Less Erosion, Environmental Recovery in Kenya. ACTS Press (African Centre for Technology Studies), Nairobi, Kenya.

UNEP, 2009. An Assessment of Hydrological and Land Use Characteristics Affecting River-Coast Interactions in the Western Indian Ocean Region, Nairobi Convention Secretariat and WIOMSA. UNEP. Nairobi.

URT, 2002. National Water Policy. Ministry of Water and Livestock Development, Dar es Salaam, United Republic of Tanzania.

Van Koppen, B., Sokile, C. S., Hatibu, N., Lankford, B. A., Mahoo, H. and Yanda, P. Z., 2004. Formal Water Rights in Rural Tanzania: Deepening the Dichotomy? International Water Management Institute Working Paper 71.

Yanda, P. Z. and Shishira, E. K., 2001. Forestry conservation and resource utilisation on southern slopes of Mount Kilimanjaro: trends, conflicts and resolutions.

Water Management in Pangani River Basin, Research Monograph, 1(3). Dar Es Salaam University Press, Dar es Salaam.

Zolongo, S. A., Kiluvia, S. and Mghase, G., 2000. Umbwe Onana PRA Report. Traditional Irrigation and Environmental Development Organization, Moshi. 